\title{
REDES DE POLÍTICAS PÚBLICAS E DE GOVERNANÇA E SUAANÁLISE A PARTIR DA WEBSPHERE ANALYSIS ${ }^{1}$
}

\author{
Mario Procopiuck
}

\author{
Klaus Frey
}

\begin{abstract}
RESUMO
Com o presente artigo propõe-se uma discussão sobre a Policy Websphere Analysis como abordagem metodológica de análise de arranjos organizacionais e suas relações expressas no ciberespaço, buscando explicitar lógicas de políticas públicas em contexto de redes de politicas. Sob essa abordagem, serão apresentados resultados de uma pesquisa que buscou apreender e interpretar a lógica relacional, sustentada em valores e normas subjacentes aos arranjos organizacionais, das práticas sociopoliticas destinadas a viabilizar a difusão social de Tecnologias de Informação e Comunicação (TICs) em Porto Alegre e Curitiba. Será apresentada a morfologia reticular de tais arranjos, por meio de gráficos construídos a partir de sitios de Internet e hyperlinks, que, em essência, constituem-se em meios representativos de potenciais espaços de interação política e de valores sociopolíticos comunicados por organizações articuladas em arranjos de governança representados na esfera virtual. Entendemos que a mais importante contribuição da Policy Websphere Analysis para a compreensão da esfera pública contemporânea, pelo menos até este momento, consiste na possibilidade de delineamento dos novos espaços de apresentação e discussão de informações, idéias, ações e projetos, tendo estes espaços crescente importância para a atuação das redes de políticas em processos de governança pública.
\end{abstract}

PALAVRAS-CHAVE: Policy Websphere Analysis; Hyperlink Analysis; Social Network Analysis; Redes Sociotécnicas de Políticas; governança pública.

\section{INTRODUÇÃO}

Este artigo pretende contribuir para a discussão sobre as possibilidades de análise de arranjos organizacionais e suas relações expressas no ciberespaço, enfatizando o potencial da policy

\footnotetext{
1 Este artigo está baseado em resultados dos projetos de pesquisa Governança e redes sociais na era digital, sob coordenação do Professor Klaus Frey e financiado pelo Conselho Nacional de Desenvolvimento Científico e Tecnológico (CNPq); Redes técno-sociais e a gestão democrática da cidade, com coordenação-geral da Professora Tamara Egler (cf. EGLER, 2006), que contou com o apoio do Fundo Regional para o Desenvolvimento da Internet para a América Latina e o Caribe (FRIDA-LACNIC); e da Dissertação de Mestrado em Gestão Urbana, de Mario Procopiuck, apresentada na Pontifícia Universidade Católica do Paraná (PUC-PR) (cf. PROCOPIUCK, 2007). Uma primeira versão deste artigo foi apresentada no Seminário Temático 25 - Políticas públicas: métodos e análises -, do XXXI Encontro Anual da Associação Nacional de PósGraduação e Pesquisa em Ciências Sociais (Anpocs), realizado entre 22 e 26 de outubro de 2007, em Caxambu, Minas Gerais.
}

websphere analysis como abordagem metodológica capaz de explicitar a formação e articulação de redes de políticas públicas apoiadas na Web. $\mathrm{O}$ estudo de complexos contextos sociopolíticos em que se articulam diferentes atores para concretizar ações junto a comunidades locais passa a requerer sofisticadas abordagens metodológicas, de cunho tanto qualitativo quanto quantitativo. É importante que tais abordagens permitam levar em consideração aspectos sociológicos, políticos, tecnológicos e ideológicos que sustentam e dão sentido aos fluxos informacionais estruturantes de arranjos organizacionais sob lógica reticular.

Nesses arranjos, a interatividade comunicativa passa crescentemente a catalisar forças com potencial de gerar, ampliar e democratizar novos espaços de governança pública emergentes da formação de constelações sociopolíticas compostas por atores públicos, semipúblicos e privados, todos com interesses diversos, mas convergindo para determinadas esferas da vida sociopolítica. Nessa perspectiva é que, em termos teóricos, propõe-se, neste artigo, a abordagem da Policy 
Websphere Analysis para a identificação, delineamento e análise das emergentes esferas públicas virtuais que se formam em torno de políticas públicas específicas.

Como tentativa de melhor compreender a realidade das estruturas relacionais delineadas no ciberespaço por organizações atuantes na política de difusão social de Tecnologias de Informação e Comunicação nas cidades de Curitiba e Porto Alegre, o presente artigo, com base na análise de dados obtidos em pesquisa empírica, tem por objetivo: 1) apresentar métodos de aplicação da abordagem Policy Websphere Analysis para identificar, visualizar e analisar as novas configurações de redes sociotécnicas de políticas; e 2) apresentar e analisar uma rede de atores de governança, procurando compreender as relações, expressas no ciberespaço, entre organizações do setor público, do setor privado e do terceiro setor com relevância para a governança no âmbito da política em questão.

\section{ABORDAGEM TEÓRICO-CONCEITUAL PARA O ESTUDO DAS REDES SOCIOTÉC- NICAS DE POLÍTICAS}

Nesta seção do trabalho são inicialmente apresentados alguns fundamentos da análise de políticas públicas; na seqüência, é discutida a abordagem das redes de políticas públicas como ferramental de análise das novas práticas de governança em sistemas sociais policêntricos; finalmente, pretendemos formular o atual desafio inerente ao estudo de redes sociotécnicas de políticas.

Com vistas a explicitar efeitos e explicar leis e princípios próprios das políticas, os estudos envolvendo políticas públicas no Brasil, principalmente até as últimas décadas do século passado, tenderam a ser descritivos e com distintos graus de complexidade analítica e metodológica. Muitas vezes foram conduzidos de modo dissociado de macroprocessos, centrando-se em microabordagens tendentes a realçar análises estruturais com foco voltado para instituições, ou procuravam delinear processos de negociação restritos a políticas setoriais específicas (FREY, 2000, p. 213-214).

Mais recentemente, como alternativas metodológicas para a investigação de políticas públicas, foram propostas novas abordagens, como o fez Frey (2000) ao tratar da Policy
Analysis como instrumento analítico capaz de realçar a dinâmica relacional típica de políticas conflitivas que se desenvolvem em contextos sociopolíticos crescentemente interativos e nos quais diferentes tipos de atores buscam alcançar, ao mesmo tempo, resultados particulares e coletivos. A Policy Analysis permite, pois, abordar simultaneamente as inter-relações institucionais, os processos políticos e o conteúdo da política articulada.

A Policy Analysis compreende procedimentos metodológicos que visam identificar e apreender elementos formadores ou constitutivos da complexa esfera de ação sociopolítica em distintas atividades analiticamente manejáveis. $\mathrm{O}$ enfoque da Policy Analysis permite descrever as relações internas e os contornos externos, por mais tênues que sejam, das redes político-administrativas compostas por diferentes tipos de atores pertencentes ao setor público, ao setor privado e à sociedade civil organizada.

A abordagem em questão permite a observação de microprocessos sem ignorar sua inserção em macroprocessos de elaboração e execução de políticas e de programas articulados em uma esfera pública ampliada. Com isso, facilita a identificação das instituições envolvidas, das perspectivas estratégicas por elas adotadas e dos fluxos de diferentes recursos que as ligam e as tornam interdependentes em processos sociopolíticos particulares, para cujas características o foco de análise é voltado.

A Policy Analysis, portanto, tem por objetivo uma melhor compreensão da complexidade relacional, cada vez mais interativa e dinâmica, do sistema político-administrativo em ação, ou seja, na elaboração e execução de políticas públicas. Além disso, oferece importantes instrumentos avaliativos desenhados especialmente para a obtenção de subsídios para o aprimoramento da gestão pública e dos processos políticos ao permitir pôr em evidência o posicionamento dos diferentes atores e os efeitos de suas decisões no seu entorno relacional.

Com este enfoque da Policy Analysis, é possível, por conseguinte, ampliar a abrangência analítica, superando limitações impostas pelas abordagens que se restringem a considerar isoladamente a dimensão institucional (polity) ou a dimensão político-processual (politics) da política. 
A Policy Analysis caracteriza-se justamente por permitir a confluência dessas duas dimensões e seu tratamento concomitante com a dinâmica das ações estratégicas envolvidas em redes (FREY, 2000; MARQUES, 2003, p. 18), sendo estas estruturadas com lastro em valores simbólicos que interferem nos fins da articulação coletiva, nos fluxos materiais e imateriais e nos meios relacionais, utilizados com propósitos voltados ao alcance de objetivos conjuntos em dados contextos sociopolíticos.

A abordagem das redes de políticas, por um lado, oferece bases teórico-conceituais que permitem a apreensão, com maior grau de objetividade, de processos e estruturas na elaboração e execução de políticas públicas, os quais ocorrem em um ambiente político de crescente fluidez institucional. Por outro lado, passam a oferecer ferramental metodológico que permite apreender relações empiricamente observáveis e, a partir disso, representar agrupamentos (clusters), processos de intercâmbio de recursos, fluxos de influências, interdependências de metas e objetivos; e, finalmente, analisá-los sob as diferentes perspectivas dos atores envolvidos. Com isso, é possível definir e analisar posicionamentos dos atores coletivos ou individuais na respectiva estrutura reticular, sendo esta estrutura constituída a partir da confluência de interesses condicionados por valores coletivos comuns e, pelo menos parcialmente, conflitantes.

Em termos metodológicos, sob a perspectiva das redes de políticas, em primeiro lugar, é identificado o conteúdo a partir do qual se define o contexto e o escopo em que os jogos políticos são travados e, subseqüentemente, é possível a apreensão de ações colaborativas relacionadas a processos interativos convergentes para determinadas assuntos ou interesses. Ao tratar processualmente tais interações, como constitutivas do ciclo das políticas, as redes de políticas podem ser vistas sob influências de conjuntos de regras formais e informais que governam as interações entre o Estado e os interesses organizados. Essas regras, nesse processo, podem ser qualificadas como instituições por normalmente serem de natureza geral, basearem-se em práticas e significados compartilhados, serem de conhecimento da maioria dos atores e por se estruturarem e estabilizarem-se em decorrência de repetitivas interações em redes (MARCH \& OLSEN, 1994, p. 250).
Essas regras constituem-se em condicionantes que servem de diretrizes para o comportamento estratégico dos atores políticos, voltado ao delineamento e execução de ações formais e informais desses atores em determinada esfera ou setor da política.

Considerando concomitantemente o conteúdo material que define o escopo de uma dada política e seu âmbito institucional, que interfere na sua lógica e dinâmica processual, torna-se possível identificar e analisar as configurações de redes temáticas, de maior ou menor grau de abertura. A estrutura relacional típica das redes de políticas é passível de se revestir de identidade própria, frente a outras configurações, pela possibilidade da participação ser tendencialmente mais ampla e aberta. O fluxo de entrada e saída de atores, cada um com seus diferentes pontos de vista sobre os resultados, tende a tornar as interações fluídas e formar uma ampla gama de centros instáveis de tomada de decisão. Em contrapartida, há menos contatos formalmente institucionalizados entre grupos e governos - portanto, menos regras formais a serem necessariamente seguidas. Logo, tendem a existir tentativas de imposição de pontos de vista e/ou negociações de compromissos no processo de tomada de decisão, uma vez que a unanimidade é raramente possível. Os canais de comunicação são caracterizados por os atores poderem expressar publicamente suas opiniões, sem, contudo, possuírem qualquer garantia de que serão seguidos pelos demais. Isso dependerá da força de convencimento de seus argumentos e da credibilidade e reputação institucional ou pessoal de cada ator. Nas redes temáticas abertas, a recompensa dos atores reside na possibilidade de influenciarem os resultados da política.

Diante de tais características é mais provável que nessas redes a elaboração de políticas de caráter público seja mais plural e com tendência a maiores possibilidades de conflitos. Aliado a isso, elas tendem a desenvolver-se geralmente em novas áreas em que inexiste um grupo dominante $\mathrm{e}$ onde não há instituições formalmente estabelecidas que possibilitem a exclusão de interessados (BLOM-HANSEN, 1997, p. 676; EVANS, 1998; KLIJN, 1999; ZURBRIGGEN, 2005). Nas novas arenas públicas interativas em surgimento, os atores buscam, portanto, interferir estratégica e articuladamente em diferentes dimensões da política com vistas a formular, defender e selecionar cur- 
sos de ação destinados à resolução de problemas em questões substantivas da vida sociopolítica. É importante frisar que, nesse contexto, de acordo com Windhoff-Héritier (1987), Prittwitz, (1994) e Frey (2000, p. 221-222), mesmo que, em geral, as barreiras de acesso às redes de políticas costumeiramente sejam baixas, se comparadas com as estruturas institucionalizadas da política, existem redes em que o número de envolvidos tende a ser pequeno e as barreiras de acesso, altas.

Nessas estruturas de organização para articulação sociopolítica, conseqüentemente, os atores deixam de ser representados como simples conjuntos amorfos de participantes em eventos isolados. Em termos analíticos, passam a ser considerados ativamente a partir da gênese de sistemas relacionais que ganham forma e consistência no decorrer do tempo, originando complexas estruturas de governança com identidade própria em torno de conteúdos específicos de políticas que lhes interessam. Nessas estruturas, com diferentes níveis de coesão relacional, o posicionamento e as capacidades de articulação de cada agente individual para afetar os resultados coletivos nas decisões políticas são os meios disponíveis para interferir no curso de suas próprias ações e das dos demais atores. Nesse ponto, justamente, surge a lógica interativa das ações estratégicas individuais frente aos propósitos coletivos.

Essas esferas da política, por tais razões, passam a ser concebidas como sistemas reticulares sociopolíticos abertos em que os agentes que as integram não atuam isoladamente, mas são mutuamente influenciados em função da disponibilidade de recursos, de interesses e de estratégias que condicionam a dinâmica de negociação na formulação e execução das políticas e iniciativas. Os mútuos intercâmbios, em conseqüência das dependências de recursos durante as interações, acabam por consolidar uma estrutura relacional específica e estruturar o contexto simbólico em que as redes de políticas estão inseridas. Não é suficiente, portanto, levar em consideração, em consonância com uma visão estruturalista das redes, "os sítios identificáveis de influência e de poder", mas ao mesmo tempo é preciso contemplar "a dimensão simbólico-cognitiva e discursiva" subjacente à estrutura de governança da rede (GUALINI, 2005, p. 293).
As redes de políticas, assim, podem ser vistas como relacionadas a sistemas simbólicos. Nessa linha, Pierre Bourdieu (2005, p. 9; cap. V), ao descrever os sistemas simbólicos, os vê como instrumentos de conhecimento e de comunicação do mundo social. Neles, pois, as estruturas relacionais simbólicas condicionam as relações sociais e exercem um poder estruturante dos processos de interação nos respectivos campos sociais ou, no caso de redes de políticas públicas, campos de políticas. O poder simbólico que permeia os processos de construção da realidade tende, então, a atribuir um sentido ao mundo social. As estruturas simbólicas permitem também uma concepção tendencialmente homogênea quanto a relações lógicas que tornam possível a concordância de se chegar a um "consensus acerca do sentido do mundo social que contribui fundamentalmente para a reprodução da ordem social" (idem, p. 10); permitem também o surgimento de solidariedades sociais resultantes dos agentes sentirem-se participantes de dada função social. Esta função social não se limita a uma mera função de comunicação, mas assume uma autêntica função política. Por conseguinte, os símbolos constituem-se em "instrumentos por excelência de integração" (idem, p. 9) e servem, pois, de elementos importantes para a articulação de conhecimentos e a comunicação na estruturação do sentido do mundo social.

Como em qualquer outro espaço social, a inserção numa rede de políticas públicas significa, portanto, de um lado, identidade sociopolítica e moral, baseada em valores compartilhados, e com isso a possibilidade de atuação solidária, de outro, é resultado de relações de poder que se manifestam numa luta política permanente, "luta ao mesmo tempo teórica e prática pelo poder de conservar ou de transformar o mundo social conservando ou transformando as categorias de percepções desse mundo." (idem, p. 142). Estar em redes de políticas significa, portanto, também submissão a um campo de forças, isto é, a "um conjunto de relações de força objectivas impostas a todos os que entrem nesse campo e irredutíveis às intenções dos agentes individuais ou mesmo às interações directas entre os agentes" (idem, p. 134). A análise de redes de políticas públicas pretende justamente captar essa dinâmica relacional que caracteriza esse peculiar campo de forças sociopolíticas. 
Entretanto, na análise de redes de politicas, isto é, na captação da dinâmica e da lógica das esferas relacionais articuladas em processos particulares imersos em amplos contextos sociopolíticos, o foco pode concentrar-se nas dimensões sociais, técnicas ou simbólicas das relações estabelecidas. As redes simbólicas merecem especial atenção, principalmente pelas possibilidades por elas oferecidas para a análise das relações políticas, haja vista que "a política é o lugar, por excelência, da eficácia simbólica, acção que se exerce por sinais capazes de produzir coisas sociais e, sobretudo, grupos" (idem, p. 159). Alain Touraine (1969, p. 66) chega a afirmar que, no contexto sociopolítico, "a ação é inconcebível sem o emprego de expressões simbólicas".

As redes de políticas passam a ser vistas, então, como representação de espaços relacionais simbólicos que atribuem sentido ao conteúdo estratégico e às ações individuais e coletivas de atores envolvidos em políticas de caráter público. Essas redes, quando associadas a estruturas de redes sociais (meios relacionais em que agentes sociais articulam-se entre si por intensa comunicação e intercâmbio de recursos para formação e mobilização de grupos de interesses para execução de propósitos comuns) e às redes técnicas (infra-estruturas técnicas viabilizadas pelas novas TICs como meios interativos de intercâmbio de recursos em ações relacionais) permitem o surgimento das redes sociotécnicas de políticas.

Com a expansão da Internet, que ganhou força na década de 1990, ganham força correntes de estudos das redes sociais que passam a tratar das relações entre diferentes tipos de agentes nesse novo ambiente comunicacional interativo, surgindo daí trabalhos que abordam as redes sociotécnicas, explicitadas mediante o mapeamento de hyperlinks como meios de suporte de relações políticas e sociais entre atores (cf. PARK; BARNETT \& NAM, 2002; FOOT et alii, 2003). Tecnicamente, os hyperlinks são conceituados como mecanismos que estabelecem conexões que vão de uma página da Internet a outra, ou de uma página a um arquivo, mas normalmente a interconexão ocorre entre páginas. $\mathrm{O}$ acionamento do hyperlink é feito mediante um clique que abre ou mostra um navegador da Internet. Normalmente, os hyperlinks são também usados para baixar arquivos (download) ou abrir programas de correio eletrônico. Esses dispositivos tecnológicos, pela viabilização de interações na Internet, acabam por se configurar em elementos estruturais básicos nas relações entre sítios eletrônicos (websites) na rede mundial de computadores.

Nos estudos das relações sociais, os hyperlinks deixam de ser considerados simples dispositivos tecnológicos e passam a ser vistos como um emergente canal de informação e de comunicação interativa pelo qual valores passam a ser transmitidos entre sítios. Os hyperlinks passam, então, a ser vistos como elementos estruturais simbólicos representativos de relações entre atores na Internet, expressando virtualidades de colaboração e de troca de informações entre diferentes entidades que se estruturam no ciberespaço em redes representadas por tais dispositivos tecnológicos. Além disso, passam também a constituir-se em ferramentas por meio das quais a qualquer cidadão é permitido traçar suas rotas particulares de navegação na Internet em função de seus próprios interesses. Desta forma, quanto mais bem organizados, mais significativos e com maior número de hyperlinks, em maior número serão as alternativas disponibilizadas para os cidadãos buscarem informações no ciberespaço.

Estudos têm evidenciado que os enlaces entre os sítios da Internet não são distribuídos randomicamente no ciberespaço, mas passam a constituir comunidades ou agrupamentos (clusters), que expressam identidades em contextos simbólicos específicos nessa ampla esfera virtual (cf. PARK; BARNETT \& NAM, 2002; WALKER, 2002; PARK, 2003; PARK \& THELWALL, 2003; FRY, 2006; HEIMERIKS \& BESSELAAR，2006; ROSA; FREY \& PROCOPIUCK, 2007; PROCOPIUCK \& ROSA, 2009). Nessas comunidades virtuais têm origem as redes sociotécnicas de politicas, passíveis de serem explicitadas mediante o mapeamento dos nós (simbolizados pelos sítios eletrônicos) e dos enlaces (representados por hyperlinks) que os interconectam. Esse mapeamento permite delinear e explicitar cenários simbólicos singulares - o que se denomina websphere - construídos a partir do compartilhamento de valores ou interesses comuns entre os atores. No caso da identidade da websphere ser determinada pela vinculação dos atores a um dado conteúdo de política, a partir de sua lógica relacional, tem origem uma rede sociotécnica de política, com contornos próprios. Nessa rede, sob diferentes perspectivas, po- 
dem ser identificadas posições estruturais dos diferentes atores, centrais ou periféricos, bem como captadas suas ações e intenções estratégicas declaradas em direção ao conteúdo temático das ações pretendidas ou efetivamente empreendidas.

Nessa linha, a idéia-base da Websphere Analysis ganha relevância e, portanto, justifica-se agregála às bases da Policy Analysis e da Análise de Redes Políticas, chegando, deste modo, à abordagem da Policy Websphere Analysis. Esta passa, assim, a articular perspectivas políticas, sociológicas, tecnológicas e comunicacionais no ciberespaço com vistas a apreender e interpretar realidades sociopolíticas virtualizadas ou atualizadas nessa esfera pública relacional ampliada. Sob as premissas do conceito da policy websphere, recorrendo às técnicas da Social Network Analysis, torna-se possível analisar as características dos atores que a compõem, o macro-ambiente simbólico por ela delimitado, bem como a distribuição espacial e posicional dos atores em função de relações de poder dentro de uma rede de politica (cf. PROCOPIUCK, 2007; PROCOPIUCK \& FREY, 2007). A Policy Websphere Analysis, portanto, permite descrever e analisar essas novas configurações de esferas públicas e processos políticos interativos no âmbito do ciberespaço, revelando o papel facilitador da tecnologia na promoção de novos espaços públicos que ganham expressão a partir da representação de relações ocorridas na realidade concreta, que apenas tornaram-se possíveis ou mais efetivas por meio do uso da Internet.

\section{DEFINIÇÃO DE POLICY WEBSPHERE}

Conceitualmente, na policy websphere, que funciona como uma macro-unidade de análise, a Internet deixa de ser vista como uma simples coleção de sítios eletrônicos, e passa a ser concebida como um conjunto interconectado de recursos digitais que se expandem por múltiplos sítios e são considerados relevantes ou relacionados a um "objeto", um tema ou uma política específica. Essa perspectiva possibilita a análise de realidades delineadas em função de conteúdos temáticos, sendo as relações entre produtores e usuários mediadas e potencializadas por elementos estruturais característicos dos sítios eletrônicos, os chamados hyperlinks.

Uma policy websphere pode ser concebida como uma matriz que traduz, no ciberespaço, conjuntos de significados socialmente construídos, logicamente relacionados, e passíveis de serem individualmente captados e interpretados. Uma policy websphere situa-se como um meio informacional e, ao mesmo tempo, de expressão de articulações estratégicas voltadas à obtenção de legitimação e integração reflexiva em meio a outros distintos processos institucionais implexos em amplos contextos de relações sociopolíticas. Os papéis expressos na policy websphere em tais contextos explicitam, assim, modos de participação em um universo que inclui e transcende a ordem institucional. Nessa esfera da manifestação sociopolítica no ciberespaço, são virtualmente dispostos e passíveis a serem localizados acontecimentos coletivos, incluindo ações passadas, presentes e perspectivas estratégicas futuras dos atores nelas envolvidos. As informações que circulam na websphere registram a memória de valores compartilhados pelos atores e servem para informá-los e atribuir legitimidade às ações desenvolvidas coletivamente. Em relação ao futuro, nelas são estabelecidos amplos quadros de referência para ações coletivas vindouras.

Em termos práticos, as fronteiras da policy websphere são delimitadas pela estrutura relacional formada por um conjunto de sítios vinculado a um conteúdo temático específico dentro de um contexto espacial e temporal sob investigação. Os sítios eletrônicos relacionados ao objeto ou ao tema da pesquisa são identificados, capturados no seu contexto, indexados digitalmente, preferencialmente com alguma periodicidade para análises retrospectivas, contemporâneas e/ou para projeções de cenários futuros. Dessa base de dados relacionais são extraídas informações que, por meio da aplicação de técnicas de quantificação e de classificação, são transformadas em metadados utilizados para expressar propriedades das relações entre os atores. As redes de políticas que permeiam o ambiente sociopolítico definido pela policy websphere passam a representar topologias sociais e politicas nas quais diferentes atores, com suas perspectivas sociais e ideológicas, estão implexos em ações coletivas articuladas por sistemas de governança com identidades e sentidos próprios que os distinguem dos outros.

\section{PROCEDIMENTOS METODOLÓGICOS DE} COLETA E PROCESSAMENTO DE DADOS

Para o embasamento metodológico foi tomado como suporte o processo descrito por Fábio Duarte (2002, p. 246), que compreende a apreen- 
são de uma realidade fática e sua transcrição para o universo informacional e, com base nisso, prevê a geração de modelos, a captação, a filtragem e a organização de informações expressas no ciberespaço ("desterritorializadas") para a construção e representação de um universo informacional em um ambiente computacional capaz de representar aspectos essenciais da realidade. Disso segue a necessidade de sua "reterritorialização", agora de caráter informacional, em que dados são organizados em modelos, que, por sua vez, podem ser articulados para a reconstrução de processos sociais e políticos, ou sujeitos a simulações, que podem visar a conhecer o espaço abrangido sob condições presentes, futuras ou hipotéticas.

A principal preocupação inicial da pesquisa foi buscar meios de obter dados relacionais sob determinada função capaz de mantê-los coerentes e consistentemente organizados. Com esta finalidade, foi desenvolvido um programa em ACCESS para armazenamento e processamento de informações provenientes dos sítios eletrônicos. Nesse banco de dados, foram registradas as relações representadas pelos hyperlinks que conectam tais centros nodais de informações no ciberespaço. A extração de medidas relacionais foi realizada por meio do programa UCINET (cf. ANALYTIC TECHNOLOGIES, 2002a) e a geração de grafos mediante utilização do programa NetDraw (cf. ANALYTIC TECHNOLOGIES, 2002b). Toda a coleta de dados relacionais foi realizada entre os meses de julho e agosto de 2006 e teve, como fonte exclusiva de consulta, a Internet.

O conteúdo da política tratado pela pesquisa foi definido como "difusão social de TICs" e o espaço geográfico abrangeu as cidades de Porto Alegre e Curitiba. Curitiba foi definida como a cidade de início da pesquisa e, dentro dela, como ponto de início da coleta de dados (ou de primeira ordem), buscou-se identificar uma instituição com atuação relevante na política em estudo.

Depois de definida a temática, a cobertura geográfica, desenvolvido o sistema para registro e estruturação de dados, o universo da pesquisa foi delimitado por meio da aplicação da técnica denominada "Bola de Neve", ou Snowball, cujo detalhamento operacional é descrito abaixo. $\mathrm{Na}$ aplicação desse método, há tendências de que a composição da rede a ser delineada venha a refletir características relacionais do ator inicial, haja vista que este exerce influências que determinarão a inclusão dos demais atores na rede. Por tal motivo reveste-se de grande importância a escolha de um ator, ou de um conjunto de atores, com características relacionais significativas quanto à aderência à temática em exame e à base territorial delimitada. Neste sentido, a literatura adverte que a qualidade dos dados obtidos pelo método "Bola de Neve" é condicionada por uma criteriosa seleção do ponto de partida natural para a coleta de dados, que bem represente as características das relações entre os atores dentro da população estudada (SCOTT, 2000; HANNEMAN \& RIDDLE, 2005).

Sob tais premissas, procurou-se identificar uma instituição com atuação representativa na formulação e execução de políticas de difusão social de TICs em âmbito local. Com este objetivo foi dado início a levantamentos na Internet, por meio da utilização da ferramenta de buscas Google, e acessados os sítios eletrônicos de instituições localizadas em Curitiba e atuantes na política de difusão social de TICs. Na análise, e com apoio em conhecimentos prévios dos pesquisadores, foi considerada a representatividade das suas relações com outras instituições em nível local, regional, nacional ou internacional, expressas no ciberespaço.

A partir de tais procedimentos, decidiu-se iniciar os trabalhos de coleta de dados a partir do sítio do Instituto Curitiba de Informática (ICI). Este instituto é o principal fornecedor de infraestrutura, representada por equipamentos e pessoal técnico especializado, para atender às necessidades da Prefeitura Municipal de Curitiba que envolvam a aplicação de TICs para condução de políticas públicas locais. Aliado à representatividade do ICI na condução da política local de difusão social de TICs, ao analisar seu sítio eletrônico, foi também constatado o registro de vários projetos e um número significativo de hyperlinks que o conectam com importantes instituições públicas, privadas e do terceiro setor envolvidas com tais políticas em âmbito local e supra-local.

Em termos procedimentais, desde o ponto inicial da coleta de dados, os hyperlinks identificados nos sítios pesquisados eram acedidos e, de- 
pois de analisados, classificados estruturalmente como relacionados ao conteúdo temático da pes- quisa. A definição de cada um desses três tipos de hyperlinks consta do Quadro 1, a seguir.

\section{QUADRO 1 - CATEGORIAS RELACIONAIS ENTRE ATORES}

\begin{tabular}{|c|c|c|}
\hline $\begin{array}{l}\text { TIPO DE } \\
\text { RELAÇ̆̈O }\end{array}$ & DEF INIÇÃO & $\begin{array}{c}\text { REDE } \\
\text { ORIGINADA }\end{array}$ \\
\hline $\begin{array}{l}\text { Atores } \\
\text { Nucleares }\end{array}$ & $\begin{array}{l}\text { Sẫo hperönks que relacionam instituiçốes com objetivos e missốes } \\
\text { declaradas quanto ao envolvimento em políticas de difusẫo social das } \\
\text { TICs nas cidades de Porto Alegre e iou Curitiba; }, \text { ainda, com projetos ou } \\
\text { açốes concretas sendo realizadas em quaisquer destas duas cidades. }\end{array}$ & $\begin{array}{l}\text { Rede de } \\
\text { Atores } \\
\text { Nucleares }\end{array}$ \\
\hline $\begin{array}{l}\text { Parc eiros } \\
\text { Temáticos }\end{array}$ & $\begin{array}{c}\text { São hyperỉnks que relacionam instituiçỗes com objetivos e missỗes } \\
\text { declaradas em direção às políticas de difusấo social das TICs nas cidades } \\
\text { de Porto Alegre eiou Curitiba, mas sem nelas possuírem partic ipaçẫo em } \\
\text { açốes ou projetos. }\end{array}$ & $\begin{array}{l}\text { Rede de } \\
\text { Parcerias } \\
\text { Temáticas }\end{array}$ \\
\hline $\begin{array}{l}\text { Hyperinkis } \\
\text { de } \\
\text { Referência }\end{array}$ & $\begin{array}{l}\text { Sẫo todos os hyperijks que partiam dos sítios das instituções nucieares, } \\
\text { identificados como canais de comunicação com instituiçốes que } \\
\text { evidenciaram nẫo possuir atuaçẫo continuada na política de difusẫo social } \\
\text { de TICs em Porto Alegre ejou Curitiba. Nesta categoria foram } \\
\text { classificados aqueles atores com participaçốes pontuais em determinadas } \\
\text { iniciativas. Tais instituiçốes normalmente sẫo citadas como atuantes em } \\
\text { açốes e projetos na condiçẫo de eventuais patrocinadores ou apoiadores, } \\
\text { sem apresentar, em seus respectivos sitios, missốes ou objetivos } \\
\text { permanentes vinculados às políticas em estudo. }\end{array}$ & $\begin{array}{l}\text { Rede de } \\
\text { Ayperinks } \\
\quad \text { de } \\
\text { Referência }\end{array}$ \\
\hline
\end{tabular}

FONTE: Os autores.

Com suporte nas premissas classificatórias definidas no Quadro 1 foi aplicado o método "Bola de Neve". Neste processo, após identificação e classificação dos hyperlinks - que partiam do sítio eletrônico de primeira ordem - pertencentes aos atores nucleares, eram todos enquadrados como apontando para sítios de segunda ordem de atores nucleares, de parceiros temáticos ou de simples hyperlinks de referência, como representado esquematicamente na Figura 1.

Depois de acedidos todos os sítios apontados por aquele de primeira ordem, eram então avaliados os respectivos conteúdos e feita a sua classi- ficação com fundamento nos conceitos trazidos no Quadro 1. Das três possibilidades de classificação, eram selecionados aqueles sítios cujos atores enquadravam-se na categoria atores nucleares. Estes passavam então a constituir-se em referencial para aceder os sítios de terceira ordem. Em relação a estes, eram aplicados os mesmos critérios classificatórios a que se submeteram os de segunda ordem. Esse procedimento foi aplicado sucessivamente até o esgotamento das possibilidades de surgimento de novas instituições que preenchessem as condições para serem incluídas na ordem seguinte.

\section{FIGURA 1 - REPRESENTAÇÃO ESQUEMÁTICA DO PROCEDIMENTO DE COLETA DE DADOS}

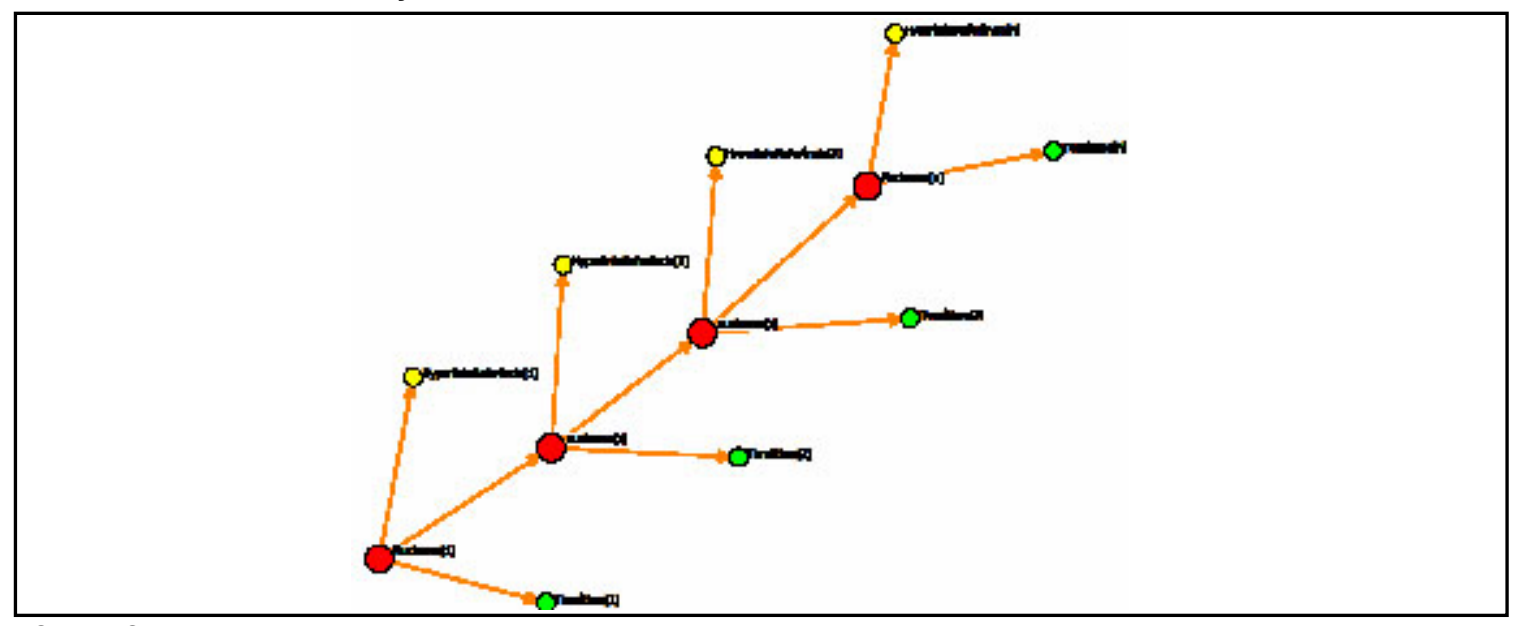

FONTE: Os autores. 
Dos sitios pertencentes aos atores nucleares foram registrados os dados institucionais arrolados e definidos no Quadro 2, que se configuram como atributos individuais dos atores. Os dados coletados de acordo com as diretrizes trazidas neste quadro passaram a constituir o substrato analítico por meio do qual foi possível classificar, segundo a tipologia expressa no Quadro 1, as relações de cada um dos 311 sitios pesquisados.

\section{QUADRO 2 -ATRIBUTOS INDIVIDUAIS DOS ATORES NUCLEARES PESQUISADOS}

\begin{tabular}{|c|c|}
\hline ATRIBUTO & DESCRIÇÃO \\
\hline Nome & Nome da instituiçẫo. \\
\hline $\begin{array}{l}\text { Endereço } \\
\text { eletrônico }\end{array}$ & Endereço do sítio na Internet ou URL \\
\hline $\begin{array}{l}\text { Abrangência } \\
\text { da Atuaçấo }\end{array}$ & $\begin{array}{c}\text { Em relaçẫo a cada ator pesquisado foi avaliada a abrangênc ia de sua atuaçẫo, } \\
\text { considerando as cidades de Porto Alegre elou Curitiba. }\end{array}$ \\
\hline $\begin{array}{l}\text { Escala de } \\
\text { Atuaçẫo }\end{array}$ & $\begin{array}{l}\text { Para cada sítio, a escala de atuaçẫo foi classific ada em "local", "regional", "nacional" } \\
\text { ou "internacional". Esses atributos foram definidos previamente à coleta de dados. }\end{array}$ \\
\hline $\begin{array}{l}\text { Setor de } \\
\text { Atuaçẫo }\end{array}$ & $\begin{array}{l}\text { Os atores pesquisados foram classificados como "pertencentes ao setor público", ao } \\
\text { "setor privado" ou ao "terceiro setor". A definiçẫo desses atributos para classificaçẫo } \\
\text { foi efetuada previamente ao início da pesquisa. }\end{array}$ \\
\hline Missẫo & $\begin{array}{c}\text { Ao tempo em que os sítios eletrônicos dos atores eram acedidos e considerados } \\
\text { como pertencentes ao universo dos atores nucleares da pesquisa, era identific ada e } \\
\text { transcrita a sua missấo declarada quanto à sua atuaçấo no campo das polític as de } \\
\text { difusẫo social das TICs, bem como quanto aos objetw os buscados em açốes } \\
\text { desenvolvidas em tal campo. }\end{array}$ \\
\hline $\begin{array}{l}\text { Políticas ou } \\
\text { áreas de } \\
\text { interesse }\end{array}$ & $\begin{array}{l}\text { Foram identific adas e cadastradas todas as políticas sociais nas quais o ator dec larou } \\
\text { explicitamente atuar ou, na falta desta declaraçẫo, foi feita a classificaçẫo de acordo } \\
\text { com o contexto descrito da atuaçẫo. }\end{array}$ \\
\hline Objetwos & $\begin{array}{l}\text { Foram identificados e cadastrados os objetwos declarados pelos atores que } \\
\text { espelhassem suas intençốes relativamente às políticas de difusăo social das TICs. }\end{array}$ \\
\hline Projetos & $\begin{array}{l}\text { Foram registrados os seguintes dados dos projetos identificados nos sítios: nome, } \\
\text { objetwo, cidades abrangidas (Porto Alegre el ou Curitiba) e atores erwolvidos. }\end{array}$ \\
\hline
\end{tabular}

Derivada da convergência de iniciativas espelhando ações ou projetos em execução nas cidades de Porto Alegre e/ou Curitiba - dos atores classificados em qualquer das três categorias trazidas pelo Quadro 1, foi definida uma quarta categoria relacional chamada de parcerias em ações e projetos, definida no Quadro 3.

QUADRO 3-CONVERGÊNCIA DE ATORES PARA PARCERIAS EM AÇÕES E PROJETOS

\begin{tabular}{|c|c|}
\hline $\begin{array}{l}\text { TIPO DA } \\
\text { RELAÇÄ́O }\end{array}$ & DEF INIÇÃO \\
\hline \multirow[t]{2}{*}{$\begin{array}{l}\text { Parc erias em Açốes } \\
\text { e Projetos }\end{array}$} & $\begin{array}{c}\text { Sẫo espaços de corvergência de açổes empreendidas e com resultados } \\
\text { concretos produzidos no âmbito das comunidades locais tanto por atores } \\
\text { nucieares quanto pelos demais parc eiros na política de difusấo social de TICs } \\
\text { nas cidades de Porto Alegre ejou Curitiba. }\end{array}$ \\
\hline & $\begin{array}{l}\text { Importante observar que, como se trata de pesquisa relacional entre atores, } \\
\text { somente foram considerados os projetos em que os sitios indicassem pelo menos } \\
\text { um ator externo envolvido. Desta forma, foram desconsideradas todas aquelas } \\
\text { iniciativ as conduzidas indwidualmente pelos atores pesquisados. }\end{array}$ \\
\hline
\end{tabular}

FONTE: Os autores. 
Na categoria definida no Quadro 3, o critério básico utilizado para enquadramento dos hyperlinks foi a constatação de atuação concreta da organização por eles apontada em ações ou projetos de difusão social de TICs em Porto Alegre e/ ou Curitiba. Sob esse critério, portanto, foram consideradas as relações tanto de atores nucleares e parceiros temáticos quanto de hyperlinks de referência.

\section{FORMAÇÃO DE UMAPOLICY WEBSPHERE A PARTIR DE UMA REDE DE DIFUSÃO SO- CIAL DE TICS.}

Uma policy websphere pode emergir a partir de relações cooperativas previamente existentes em redes de políticas públicas ou impulsionada por eventos específicos que originam um processo de articulação via Web. Como exemplo de um processo de sedimentação de normas e valores com a finalidade de consolidação de uma esfera $W e b$ de política pode ser tomada a $V$ Oficina de Inclusão Digital, de 2006, que deu origem à Carta de Porto Alegre: Por um compromisso com a Inclusão Digital no Brasil, elaborada sob as diretrizes do Plano de Ação da Cúpula Mundial sobre a Sociedade da Informação, de 2003, que, por sua vez, busca o desenvolvimento de uma Sociedade da Informação que inclua a todos, permitindo o amplo acesso às TICs. Nessa mesma linha, mais recentemente, na Conferência Mundial sobre a Sociedade da Informação, realizada em duas etapas, em Genebra (2003) e em Tunis (2005), uma pluralidade de atores globais reuniuse para a redefinição de papéis e regras de governança exercida sobre a Internet, o livre acesso à informação, com discussões sobre exclusão e inclusão digital, dentre outros assuntos.

Movimentos e eventos como os citados constituem-se e buscam instituir sistemas de referências estruturados por intermédio da adoção de estratégias simbólicas pelas quais os agentes líderes do movimento procuram explicitar a sua visão do mundo social, dos problemas ou tópicos de interesse, de modo a definir claros contornos do seu espaço de atuação. Com isso, intentam mobilizar, catalisar e coordenar esforços coletivos para a ação sociopolítica dentro de estruturas emergentes de governança para definição de diretrizes globais de referência e de suporte a iniciativas locais, que, de outro modo, tenderiam a permanecer isoladas ou desconectadas. Exemplo desse tipo de estratégia de ação simbólica de reforço de valores sociopolíticos é a Conferência Mundial sobre a Sociedade da Informação de 2005, como pode ser verificado no seguinte excerto: "Além dos embates naturais que surgem com a questão do acesso à informação, o evento tornou-se simbolicamente sensível em razão da escolha do local para essa segunda fase da Conferência. O paradoxo é evidente: a Tunísia, conhecida pelo desrespeito constante de liberdades individuais, incluindo restrições severas à veiculação de informação na Internet, recebe atualmente os delegados de vários países para uma conferência sobre acesso à informação.

Em razão desses paradoxos, a Anistia Internacional, tradicional militante na defesa dos direitos humanos, lançou uma campanha em seu website com o objetivo de acabar com as restrições à liberdade de expressão e ao acesso à informação no país. O website da ONG conta atualmente com um longo relatório de monitoramento sobre a proteção de direitos humanos na Tunísia" (A TUNÍSIA EA CONFERÊNCIA INTERNACIONAL, 2005).

As intenções e recomendações expressas por tais movimentos sociopolíticos culminam por se tornar referência para a formação e o reconhecimento de domínios de políticas e, como diretrizes, para a mobilização e estruturação da ação de atores articulados para a consecução de iniciativas e projetos comuns, como é o caso da difusão social de TICs; ou, indo além, como se depreende do seguinte trecho: "[...] é preciso reconhecer que as contradições do mundo atual permitiram, pelo menos, uma unificação no discurso das ONGs ligadas à proteção de direitos humanos e as suas irmãs preocupadas com o acesso à informação. Assim, de repente, defensores de prisioneiros políticos e especialistas em propriedade intelectual viram-se lado a lado e pisando sobre o mesmo barco" (idem; sem grifos no original).

Contribuindo com tais objetivos de mobilização para a ação, a Internet, como canal interativo de comunicação, tem se transformado em uma arena de intensiva expressão intencional e espontânea de identidades organizacionais específicas, que, ao serem agregadas, correlacionadas e adjungidas, passam a definir e a representar macroambientes sociais e políticos que influenciam e são influenciados pelas ações individuais e coletivas dos atores que os integram. Nesse ambiente estruturado pelas TICs, "grupos sociais se adaptam de modo a elevar sua interconectividade, con- 
solidar sua identidade e fortalecer sua capacidade para atuar em um mundo cada vez mais interdependente" (FREY, 2005, p. 184).

O conhecimento dos atores envolvidos, de suas posições relativas, de temáticas abrangidas por seus interesses e de suas intenções e ações estratégicas permitem explicitar e compreender a lógica dos arranjos de governança que lhes dão sustentação dentro de domínios de políticas. A partir disso, as redes de políticas passam a revestir-se de identidade temática e a permitir a identificação e análise de concentrações de atos, do processo de sedimentação de normas e valores comuns e a distribuição de recursos em ações e projetos desenvolvidos intencionalmente e concretizados mediante ações articuladas em que se ajustam perspectivas políticas, sociais e ideológicas.

As propostas e ações entre os atores que compõem a emergente policy websphere, em que se inserem as redes sociotécnicas de politicas, acabam por expressar certas uniformidades quanto a intenções e objetivos. Estes, depois de publicamente declarados e difundidos, tendem a se autoimpor aos seus emissores e passam a regular suas ações no contexto social. Com isso, havendo a definição da identidade da própria policy websphere e, à conta das relações assentadas em regras e valores particulares compartilhados pelos atores que a constituem, podem caracterizar e definir identidades próprias de redes sociotécnicas de políticas que nela inserem-se e entrelaçam-se.

VI. REPRESENTAÇÃO DA TOPOLOGIA DA POLICY WEBSPHERE QUE ENVOLVE UMA REDE DE DIFUSÃO SOCIAL DE TICS

A leitura e o mapeamento dos sítios, o registro e interpretação das missões institucionais, dos objetivos e dos relatos vinculados às ações sociais desenvolvidas por conjuntos de organizações em dado campo da política, tornam possíveis, além do descortinamento de amplos movimentos sociopolíticos, a identificação e avaliação daquelas que acabam por se destacar dentro de domínios ou redes sociotécnicas de política. Com a análise das relações estratégicas empreendidas e mantidas por organizações com ações no âmbito de uma policy websphere, sob a qual redes sociotécnicas de politicas ganham contornos, podem ser delineados universos de valores sociais e políticos, conforme representado graficamente na Figura 2. A policy websphere representada por essa figura resultou do mapeamento das relações de 31 atores nucleares com atuação na rede de difusão social de TICs nas cidades de Porto Alegre e Curitiba. Nela passam a ser representadas, além do espaço geográfico e do conteúdo da política inicialmente delimitados, organizações atuando em diversos outros segmentos de ações sociais e em diferentes contextos locais, nacionais e internacionais.

Na Figura 2, os losangos amarelos espelham as diferentes áreas de interesses (conteúdos temáticos ou de políticas) para as quais são direcionados hyperlinks originados nos sítios dos atores nucleares. $\mathrm{O}$ tamanho dos losangos é diretamente proporcional ao número de hyperlinks que recebem dos demais atores. A espessura das linhas é diretamente proporcional ao número de hyperlinks que partem do sítio eletrônico de cada uma das instituições nucleares em direção a outras organizações cujo foco está direcionado para diferentes políticas ou áreas de interesse. Ressalta-se que, para não comprometer a nitidez da figura, foi definido o número máximo de 15 relações refletidas em um único enlace. Deste modo, há proporcionalidade entre o número de relações e a espessura somente até este limite. Na realidade, o número de relações por instituição pode chegar a 37, como é o caso da Prefeitura de Porto Alegre em relação à Política de Difusão Social de TICs, como detalhadas quantitativamente na sociomatriz representada no Quadro 4.

A Figura 2, de pronto, exemplifica o surgimento de uma variedade de áreas de interesses às quais as organizações estão vinculadas. Tal figura, ao definir a topologia da policy websphere, bem expressa "que o espaço social é um espaço multidimensional, conjunto aberto de campos relativamente autônomos" (BOURDIEU, 2005, p. 153), ocupados por uma diversidade de atores com interesses centrados em diversos aspectos de dada esfera de ação sociopolítica. A emergência desses diversos campos, partindo da consideração dos interesses individuais das instituições que os integram, decorre do fato de "que certos interesses serão comuns a todos os membros de uma coletividade. Por outro lado, muitas áreas [...] só terão importância para alguns tipos. Estes últimos implicam uma incipiente diferenciação, pelo menos no sentido em que se atribui a esses tipos um significado estável" (BERGER \& LUCKMANN, 1985, p. 90). 
FIGURA 2 - WEBSPHERE EM QUE ESTÁ IMPLEXAA REDE DE DIFUSÃO SOCIAL DE TICS EM PORTO ALEGRE E CURITIBA

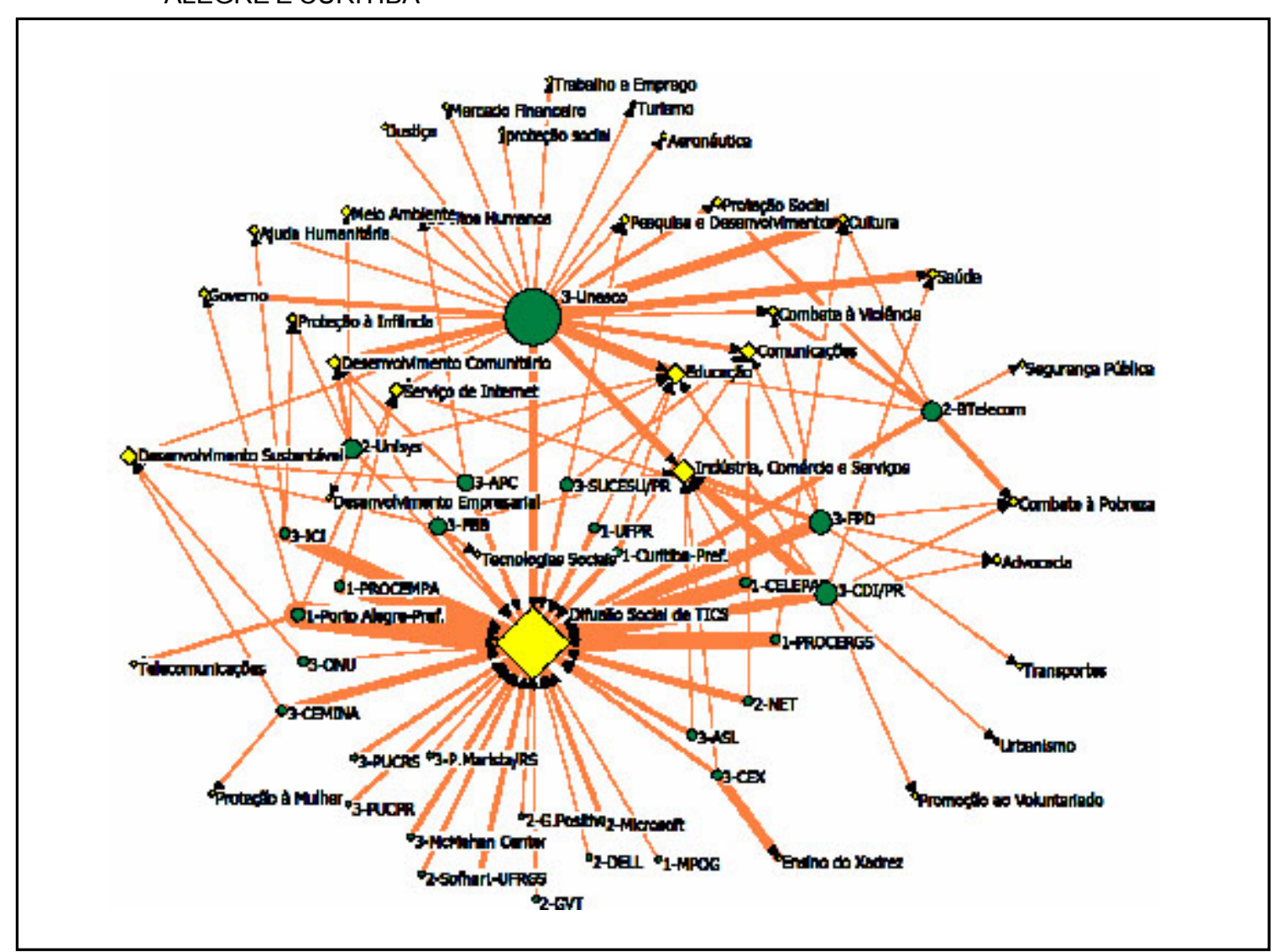

FONTE: Os autores.

Em meio à diversidade de políticas ou áreas de interesse expressas na Figura 2, surge naturalmente, como resultado do próprio método empregado para a coleta de dados, a rede de política de difusão social de TICs com posição central na policy websphere, recebendo $57 \%$ de todas as 442 relações mapeadas. No Quadro 4, é demonstrada a distribuição desse número de relações que partem dos 31 atores considerados como nucleares na rede de difusão social de TICs de Porto Alegre e Curitiba para diferentes políticas ou áreas de interesse que compõem a policy websphere. Os quantitativos e percentuais relativos às políticas de difusão social de TICs estão destacados pelas colunas acinzentadas da sociomatriz abaixo.

QUADRO 4 - POLÍTICAS OU ÁREAS DE INTERESSE DOS ATORES NUCLEARES

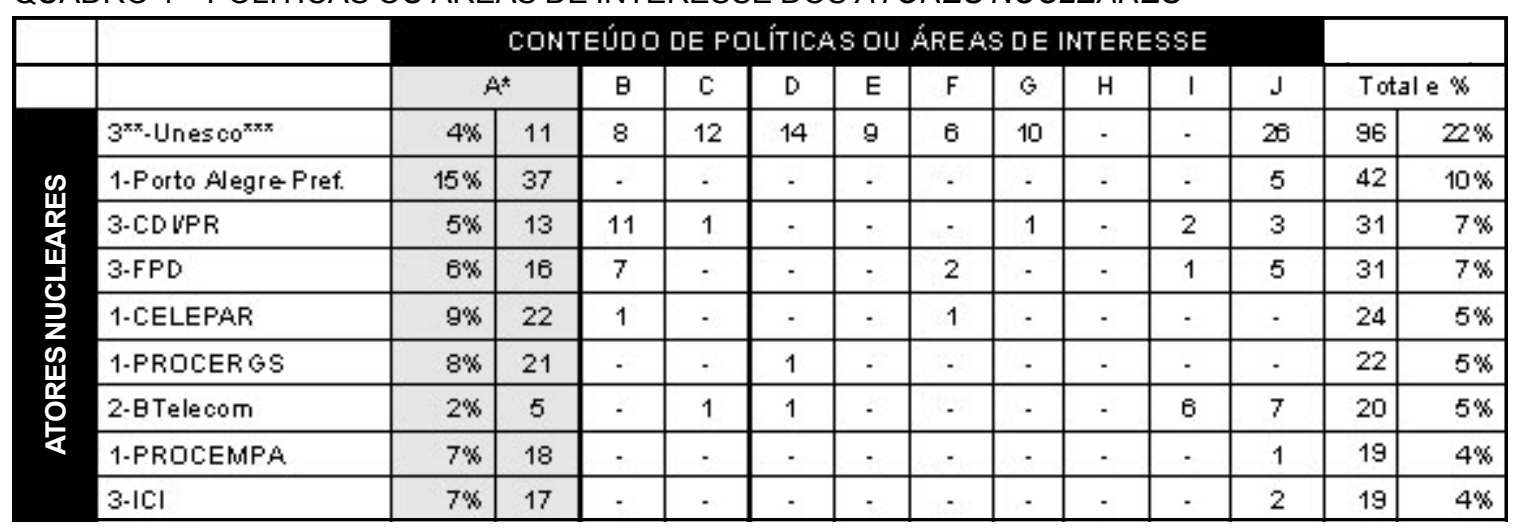




\begin{tabular}{|c|c|c|c|c|c|c|c|c|c|c|c|c|c|c|}
\hline \multirow{3}{*}{ } & 3-CEX & $2 \%$ & 4 & 2 & - & - & - & - & - & 10 & - & - & 16 & $4 \%$ \\
\hline & 2-Unisys & $1 \%$ & 2 & - & 2 & $\cdot$ & 3 & - & - & $\cdot$ & - & 5 & 12 & $3 \%$ \\
\hline & 3-CEMINA & $4 \%$ & 10 & - & - & - & - & - & - & - & - & 2 & 12 & $3 \%$ \\
\hline \multirow{4}{*}{ 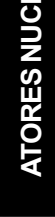 } & 3-APC & $2 \%$ & 5 & - & 1 & $\cdot$ & 2 & - & - & $\cdot$ & - & 3 & 11 & $2 \%$ \\
\hline & 2-NET & $4 \%$ & 9 & - & - & - & - & 1 & - & - & - & - & 10 & $2 \%$ \\
\hline & 1-Curitib a Pref. & $3 \%$ & 7 & - & 1 & - & - & 1 & - & - & - & - & 9 & $2 \%$ \\
\hline & $\begin{array}{l}\text { Qutras } 16 \\
\text { Organizaçốes }\end{array}$ & $22 \%$ & 57 & 4 & 1 & - & 1 & 1 & - & - & $\therefore$ & 4 & 68 & $15 \%$ \\
\hline \multirow{2}{*}{\multicolumn{2}{|c|}{ Total e $\%$}} & $100 \%$ & 254 & 33 & 19 & 16 & 15 & 12 & 11 & 10 & 9 & 63 & 442 & \\
\hline & & & $57 \%$ & $7 \%$ & $4 \%$ & $4 \%$ & $3 \%$ & $3 \%$ & $2 \%$ & $2 \%$ & $2 \%$ & $14 \%$ & & $100 \%$ \\
\hline
\end{tabular}

FONTE: Os autores.

NOTAS: * A) Difusão Social de TICS; B) Indústria, Comércio e Serviços; C) Educação; D) Cultura; E) Desenvolvimento Comunitário; F) Comunicações; G) Saúde; H) Ensino de Xadrez; I) Combate à Pobreza; J) Outras 23 áreas com oito ou menos relações:

** O número que aparece antes do nome do ator corresponde ao setor a que ele pertence: 1) Público; 2) Privado; e 3) Terceiro Setor.

*** Significado das siglas e abreviações: Unesco - Organização das Nações Unidas para a Educação, a Ciência e a Cultura; Porto Alegre-Pref. - Prefeitura Municipal de Porto Alegre; CDI-PR - Comitê para Democratização da Informática; FPD - Fundação Pensamento Digital; CELEPAR - Companhia de Informática do Paraná; PROCERGS - Companhia de Processamento de Dados do Estado do Rio Grande do Sul; BTelecom - Brasil Telecom S.A.; PROCEMPA - Companhia de Processamento de Dados do Município de Porto Alegre; ICI - Instituto Curitiba de Informática; CEX - Centro de Excelência de Xadrez; Unisys - Unisys Brasil Ltda.; CEMINA - Comunicação, Educação e Informação em Gênero; APC - Associação Paranaense de Cultura; NET - NET Brasil; Curitiba-Pref. - Prefeitura Municipal de Curitiba.

Em relação à Figura 2 e aos dados quantitativos expressos no Quadro 4, considerando os fins das ações voltadas essencialmente à elevação das possibilidades de acesso a melhores padrões locais de qualidade de vida de indivíduos de menor poder aquisitivo, verifica-se que há certa correlação e convergência entre a política de difusão social de TICs e as políticas de educação, cultura, desenvolvimento comunitário e combate à pobreza que integram a policy websphere que se explicitou. Esses espaços de convergência dentro de amplos domínios de políticas sociais aproximam-se do que Volker Schneider e Raymund Werle (1991, p. 98-99) descrevem como a configuração de um campo em que diferenciadas, mas relativamente estáveis redes de políticas estruturamse e sobrepõem-se umas às outras no processamento de problemas relacionados a políticas específicas. Essas redes, contudo, não são subsistemas nitidamente delineados, pois muitas vezes acabam por transcender os limites clássicos do domínio de uma política específica e por se sobrepor relativamente a outros domínios, sem que haja, contudo, prejuízo quanto à identificação do próprio domínio ou das próprias redes.

A complexidade das relações envolvendo diversas áreas de interesse ou políticas, como as evidenciadas pela Figura 2, para além das estrutu- ras das redes, e mesmo extrapolando a configuração de amplos domínios políticas, "em termos de sua funcionalidade social externa não precisam ser integradas em um único sistema coerente. Podem continuar a coexistir com base em desempenhos separados. Mas, [reflexamente], enquanto esses desempenhos podem ser separados, os significados [emanados de todas as ações coletivas que representam] tendem para uma consciência pelo menos mínima [do contexto, ou domínio, social mais amplo em que se inserem]...", com tendência a aumentar à medida que cada ator, com diferentes interesses, compartilha com outros seus significados em relações de "reciprocidade dotadas de sentido nos processos de institucionalização" (BERGER \& LUCKMANN, 1985, p. 91) de amplos valores sociopolíticos sobre os quais estrutura-se determinada sociedade.

Na Figura 3, são representadas as cidades em que estão localizadas geograficamente as instituições que fazem parte da policy websphere representada pela Figura 2. No Quadro 5, são quantificados os hyperlinks recebidos e que partem de cada uma das principais cidades representadas na Figura 3. A partir da sociomatriz-base da qual se originou a Figura 3, foram excluídas todas as linhas ou colunas que apresentassem somatório igual ou menor a quatro relações por 
enlace. Como resultado, foi mantida a representação de $88 \%$ das relações $(=538 \div 608)$, ou seja, deixaram de ser contempladas apenas 70 relações.

É importante notar que tanto na rede quanto no quadro abaixo são computados todos os tipos de relações entre os sítios. Isso significa que entre um par de sítios podem estar sendo contabilizadas diversas relações.

FIGURA 3 - REDE DE CIDADES ABRANGIDAS

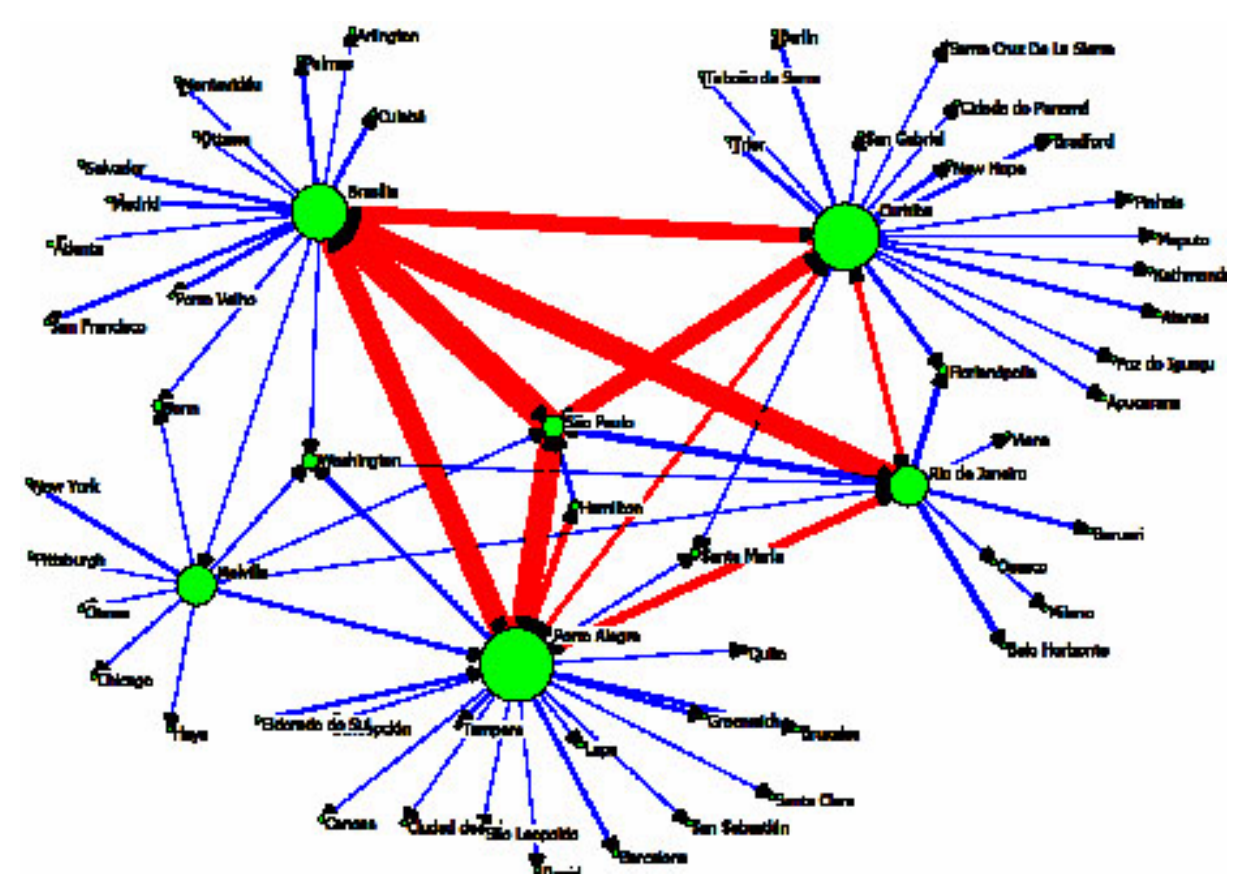

FONTE: Os autores.

QUADRO 5 - RELAÇÕES ENTRE CIDADES

\begin{tabular}{|c|c|c|c|c|c|c|c|c|c|}
\hline Cidades & 窇 & 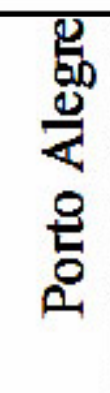 & 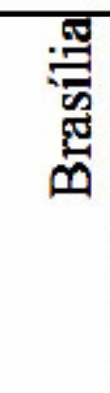 & 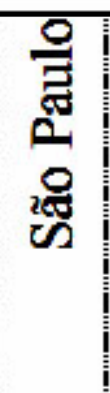 & 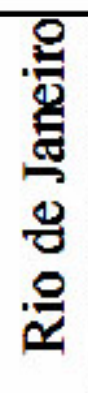 & 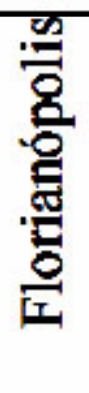 & 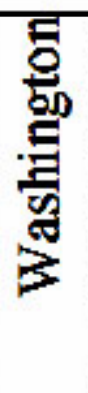 & 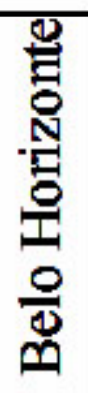 & 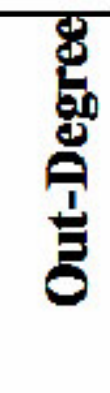 \\
\hline Curitiba & 115 & 1 & 16 & 18 & 4 & 2 & - & - & 156 \\
\hline Brasília & 6 & 21 & 64 & 30 & 26 & $=$ & 1 & $=$ & 148 \\
\hline Porto Alegre & 3 & 81 & 24 & 26 & 8 & $=$ & 3 & $=$ & 145 \\
\hline Rio de Janeiro & 4 & 4 & 13 & 7 & 8 & 4 & 1 & 4 & 45 \\
\hline Săo Paulo & 12 & 6 & 3 & 11 & - & 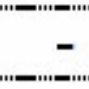 & - & - & 31 \\
\hline Hamilton & - & 6 & - & 2 & - & - & - & -" & 8 \\
\hline Melville & - & 2 & - & 1 & 1 & - & 1 & - & 5 \\
\hline In-Degree & 140 & 121 & 120 & 94 & 47 & 6 & 6 & 4 & 538 \\
\hline
\end{tabular}




\section{REDE SOCIOTÉCNICA DE POLÍTICA DE DIFUSÃO SOCIAL DE TICS IMPLEXA NA WEBSHPERE}

De modo sintético, a representação da rede de política viabilizada pela Figura 4, de acordo com parâmetros trazidos por Alain Touraine (1969, p. 63), permite, ao considerar as orientações normativas que indicam os fins buscados pelos atores, definir o sentido das relações entre sujeitos e objetos de sua ação, bem como definir as posições relativas entre sujeitos no processo de interações. Isso tudo, além de indicar a amplitude e a capacidade de ação dos sujeitos quando se trata de avaliar as articulações internas à rede sociotécnica de política que veio à tona. A amplitude temática é representada pela Figura 2, ao passo que a amplitude geográfica tem representação na Figura 3.
$\mathrm{Na}$ Figura 4, os diferentes tamanhos dos losangos amarelos variam em decorrência do número de instituições que participam da execução do respectivo projeto ou ação. Utilizando a terminologia específica da Social Network Analysis, as áreas dos losangos são proporcionais ao in-degrees de cada ação ou projeto. Os círculos simbolizam as organizações participantes na execução das ações ou projetos. A diferenciação do tamanho de cada um dos círculos é diretamente proporcional ao número de ações ou projetos em que cada uma das organizações participa: ou seja, ao out-degree de cada um dos atores ${ }^{2}$. Também, na Figura 4, há a classificação das organizações correspondente ao setor a que pertencem. Os círculos verdes identificam organizações públicas; os azuis, organizações do setor privado; e os vermelhos, organizações do terceiro setor.

\section{FIGURA 4 - REDE DE AÇÕES E PROJETOS EM PORTO ALEGRE E CURITIBA}

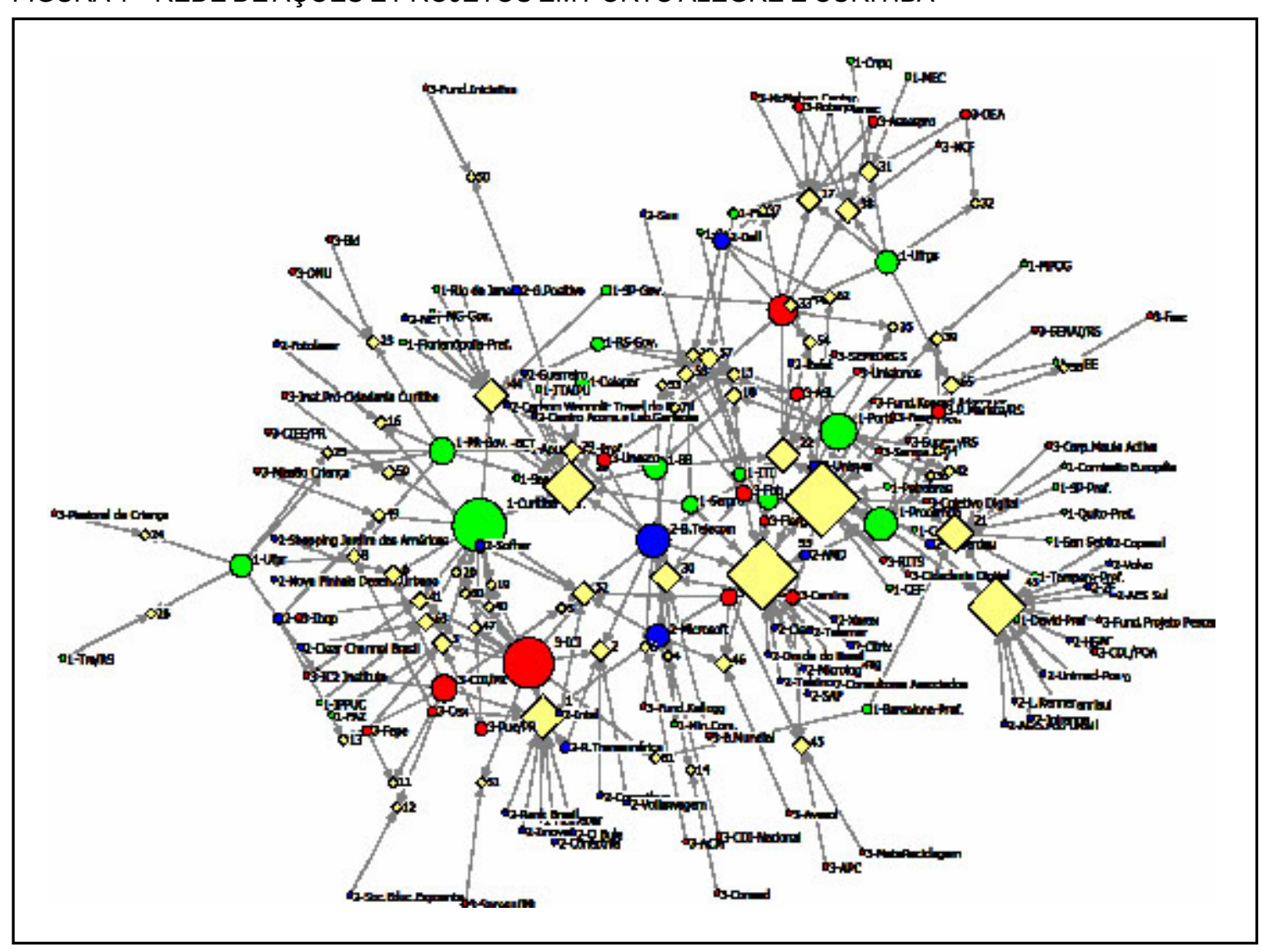

$2 \mathrm{O}$ out-degree mede a expansividade de um ator na rede, ao passo que o in-degree mede a receptividade ou popularidade desse ator (IACOBUCCI, 1997, p. 126). O in-degree pode ser denominado também de degree prestige, que re- flete a popularidade de um nó, que, por sua vez, é expressa pelo número de vezes que um ator é eleito por outros dentro da rede (WASSERMAN \& FAUST, 1997, p. 170; 202) 
A rede acima aproxima-se do que Erik-Hans Klijn (1999, p. 30) chama de conjuntos de organizações agrupadas em torno de conjuntos de ações específicas nas quais agentes sociopolíticos tentam atingir objetivos em torno de um propósito concreto em que são intercambiados recursos, almejando a obtenção de resultados estratégicos individuais e, ao mesmo tempo, comuns aos participantes.

A consideração de ações concretas para a avaliação da ação social, segundo Alain Touraine (1969, p. 19), é importante, já que uma ação social somente pode existir se estiver orientada para certos objetivos e orientações coletivas concretas. Não basta, portanto, que seja tratada somente em termos de intenções individuais; por se tratar de processo essencialmente coletivo, a ação social em rede é sustentada por sistemas de relações interativas geradoras de inovação, criação e atribuições de sentidos capazes de despertar e mobilizar novos atores por meio de sistemas simbólicos que ganham corpo a partir de realizações com reflexos concretos sobre a vida de pessoas que convivem em determinada comunidade.

$\mathrm{Na}$ Figura 4, os losangos amarelos espelham ações ou projetos em que há convergência de esforços de duas ou mais organizações. A partir da rede de difusão social de TICs, é trazido à tona um espaço interativo emergente da interação de diversos atores vinculados em virtude de uma iniciativa que se constitui em ponto de convergência que assegura unidade do funcionamento do sistema de ação visando alcançar objetivos específicos em prol de determinada comunidade.

Ao se considerar as intenções estratégicas implícitas dos atores, a Figura 4 permite visualizar globalmente uma estrutura de governança baseada em relações que condicionam uma constelação de organizações em torno de projetos dos quais participam. Também é evidenciada, à conta do número de projetos em que participam, a posição relativa de cada uma dessas organizações dentro da rede em questão. Outra informação trazida pela figura é a simbolizada pela importância relativa de cada instituição ou iniciativa; a medida in-degree, neste caso, expressa, de um lado, a capacidade de mobilização das organizações iniciadoras em favor de suas idéias e propostas e, de outro, a atratividade ou reputação de cada instituição na rede sociotécnica ou, respectivamente, das próprias idéias e propostas e da sua força de articulação e integração.
Além de permitir visualizar a macroestrutura da rede da política de difusão social de TICs nas cidades de Porto Alegre e Curitiba, a Figura 4 também serve como referencial para explorar, em nível micro, quem nela participa e a quais idéias, concepções e valores cada instituição vincula-se, sendo estes subjacentes a cada projeto ou ação representados. Em essência, a rede representada materializa um cenário de ação em que cada agente constitui-se em auxiliar, parceiro ou colaborador para os demais participantes de cada uma das 65 iniciativas. Considerando qualquer dessas iniciativas isoladamente, é possível notar que cada organização participante, em função dos processos de interação que as originaram, tem suas perspectivas objetivas e subjetivas contempladas, entretanto, em diferentes graus e com diferentes atores. Agora, se considerados atores com participação em mais de uma iniciativa, é evidenciado a sua interação com outros diferentes atores e em diferentes situações, sendo as formatações observadas resultado das peculiaridades intrínsecas de cada projeto ou ação; desta maneira, tais relações de interatividade geram um profícuo espaço para o intercâmbio de conhecimentos e experiências.

Nesse processo interativo espelhado pelas ações executadas conjuntamente pelos atores articulados em rede, agora em nível macro, descortina-se um ambiente em que há mescla de diferentes perspectivas subjetivas desses agentes. Com isso, é possível gerar uma estrutura em rede, interinstitucional e "extra-individual", revelada a partir da conjunção de diferentes valores sociais, políticos e ideológicos, resultante da participação de atores pertencentes aos setores público, privado e terceiro setor. Nesse ambiente, cada um destes três grupos de agentes comparece com suas próprias regras e valores que os distinguem política e socialmente. As diferentes perspectivas normativas que influenciam a conduta dos atores pertencentes a cada um dos setores representados neste ambiente relacional esboçado acabam por se ajustar e se conformar ao serem materializadas em ações e projetos que revertem resultados concretos no seio das comunidades locais em que se desenvolvem. Neste sentido, dão origem a um espaço para constituição de representações meta-sociais, conforme processo descrito por Peter Berger e Thomas Luckmann (1985, p. 91), que poderão determinar características peculiares que distinguirão a rede sociotécnica de política de difusão social de TICs em Porto Alegre e 
Curitiba perante outras redes estruturadas a partir de temáticas ou delimitações geográficas distintas.

Na Figura 4, verificando as diferentes cores dos nós, pode ser constatada e contabilizada a participação relativamente equilibrada dos três setores em termos numéricos nos 65 projetos e ações das, ao todo, 142 diferentes organizações. Dentre essas organizações, 46 (32\%) pertencem ao setor público; 47 (33\%) ao setor privado; e 49 (35\%) são integrantes do terceiro setor. Este equilíbrio relativo dos setores na composição da rede revela uma tendência que cada vez mais caracteriza o provimento de bens sociais e de serviços públicos básicos: um maior peso do setor privado, o que traz, de um lado, mais recursos e possibilidades de suprir as necessidades sociais crescentes, mas, de outro, aumentam também as possibilidades de uma ingerência ou predominância dos interesses econômicos na execução de políticas públicas. Esta observação tem uma peculiar relevância no caso de projetos de difusão social de TICs, uma vez que para as empresas de telecomunicações, não por acaso as empresas mais ativas nesta área, a ampliação do acesso às TICs é diretamente vinculada com seus interesses econômicos.

Analisando a Figura 4, quanto à distribuição geográfica entre as duas cidades estudadas, agora com foco nas ações e projetos, verifica-se também a existência de certo equilíbrio numérico, mas com pequeno viés em favor de Porto Alegre: 30 (46\%) das iniciativas são conduzidas nesta cidade e 27 (42\%) em Curitiba, sendo que oito (12\%) abrangem ambas as cidades.

No caso específico da política de difusão social de TICs nas cidades de Porto Alegre e Curitiba, os níveis de participação e de interação em ações conjuntas indicadas na Figura 4, por si só, sugerem terreno fértil para internalização e externalização de normas e valores entre as organizações participantes e, portanto, entre as diferentes localidades. A atuação conjunta dos atores parece indicar que estes estão mutuamente orientados para demandas de ordem social; senão, sinaliza ao menos a superação da ação puramente individual por atuações cada vez mais coletivas. De qualquer modo, há indicação da emergência de algum grau de sociabilidade e identidade compartilhada, uma vez que "o ator se identifica com um grupo, a um sujeito coletivo; superando assim, sua individualidade compartilhando normas, valores, inten- ções. Por outro lado, fortalece sua imagem perante os demais membros do grupo ao expressar sua identidade" (TOURAINE, 1969, p. 70).

Agora, por outro lado, analisando o número de ações e projetos em que cada uma das organizações representadas na Figura 4 participa, temse que $103(71 \%)$ tomam parte de apenas uma iniciativa; $15(10 \%)$ participam em duas; nove (6\%), em três; e 17 (12\%) estão vinculadas a quatro ou mais iniciativas. Essa relativamente baixa amplitude de participação em diferentes iniciativas pode ter diferentes explicações: por um lado, o fato da política de difusão social de TICs não ser a única que merece atenção da maioria das organizações envolvidas, ou até de se constituírem em organizações que têm tal participação como "acessória" das suas principais atividades ou fins institucionais (o que deve ser o caso, sobretudo, de empresas privadas que atuam motivadas primordialmente pela idéia da responsabilidade social corporativa); de outro lado, o fato de algumas organizações constituírem-se em atores iniciantes do respectivo campo de política, ou, ainda, o fato de se dedicarem única e exclusivamente a um projeto ou atividade em função da sua própria precariedade institucional (o que é uma condição de muitas organizações não-governamentais, sobretudo num campo novo como é a difusão social de TICs).

Independentemente do motivo que levou a maioria das organizações a se envolverem em iniciativas únicas, figura-se, em si, como aspecto importante dentro da política, o fato de que tais organizações foram movidas a se inserir em um ambiente de sociabilidade com finalidade de atuar cooperativa e efetivamente em busca de resultados concretos em benefício de comunidades locais. Neste ponto, abre-se uma importante perspectiva para o desenvolvimento de outros estudos mais aprofundados para buscar explicações para a realidade que se descortinou; por exemplo, com o objetivo de avaliar se há uma tendência de envolvimento de tais organizações com maior número de iniciativas com o decorrer do tempo. Nessa linha, há interessante estudo empreendido por Peter Spink (2000), que oferece importantes parâmetros comparativos quanto ao número de entidades envolvidas em iniciativas sociais no Brasil.

Finalmente, quanto à participação em iniciativas, expressando propriedades posicionais na rede, destacam-se, no quesito centralidade, a 
PROCEMPA - Empresa de Tecnologia da Informação e Comunicação de Porto Alegre -, com nove participações, e as prefeituras de Porto Alegre (10) e de Curitiba (14), no setor público; no setor privado, têm maior relevância o Banco do Brasil (seis), a Microsoft (seis) e a Brasil Telecom (nove). No terceiro setor, sobressaem-se a Fundação Pensamento Digital (oito) e o Instituto Curitiba de Informática (13 participações). Importante notar que a Fundação Pensamento Digital e, por conseqüência, as ações e projetos em que participa contam com amplo envolvimento de atores privados e do terceiro setor, ao passo que aqueles desenvolvidos pelo Instituto Curitiba de Informática contam com o envolvimento principalmente da Prefeitura Municipal de Curitiba.

\section{CONSIDERAÇÕES FINAIS}

Pretendeu-se neste artigo demonstrar o potencial da Policy Websphere Analysis em contribuir para a compreensão do novo ambiente interativo do ciberespaço no que tange à sua influência sobre as redes de políticas públicas ou de governança, as quais, diante do esgotamento do modelo "estatocêntrico" de gestão pública, tornaram-se cada vez mais dominantes tanto nas práticas de gestão como nas reflexões teóricas sobre estas.

As reflexões teóricas empreendidas neste trabalho, bem como as recentes pesquisas empíricas realizadas $^{3}$, demonstram o surgimento de relações interinstitucionais que anteriormente não existiam, mas que ainda são pouco percebidas como relevantes em processos de governança. A policy websphere mostrou-se não apenas um conceito capaz de descrever esta nova realidade (de uma crescente interconectividade no espaço virtual), mas acabou revelando uma dimensão normativa, com perspectiva prescritiva, ao permitir identificar estruturas de poder e estratégias informacionais distintas adotadas pelas diferentes instituições, além de situações de exclusão e gargalos em relação aos fluxos informacionais e comunicacionais. Neste sentido, a Policy Websphere Analysis mostrou-se como uma ferramenta capaz de auxiliar os tomadores de decisão

\footnotetext{
3 No Programa de Mestrado em Gestão Urbana, da PUCPR, no início de 2007, houve a conclusão e defesa de duas dissertações que tratavam, num caso, de políticas de difusão social de TICs (PROCOPIUCK, 2007), e, no outro, de política ambiental (ROSA, 2007), recorrendo ambas
}

no aprimoramento dos processos de governança, aumentando sua eficiência, mas também a transparência e as possibilidades de participação democrática.

O universo simbólico retratado pela policy websphere e, dentro dela, pelos referenciais individuais e coletivos que orientam as ações articuladas por redes sociotécnicas de políticas emergentes, é resultado da expressão de valores comuns institucionalizados e da sua publicização nos sítios eletrônicos que o compõem. Estes sítios, como lugares de expressão de normas e valores institucionais, apresentando relações que convergem para atividades e projetos comuns, sendo passíveis de serem mapeados pelo rastreamento dos hyperlinks que os entrelaçam no ciberespaço, passam a estruturar e a fundamentar uma identidade simbólica da policy websphere que eles integram. No ciberespaço, tendo como mecanismo de sua gênese a utilização das potencialidades trazidas pelos hyperlinks, cada policy websphere passa a representar uma topografia passível de ser navegada e investigada por qualquer interessado em função daquilo que julga importante quanto a informações correlacionadas e disponibilizadas relativamente à temática e aos contornos geográficos que lhe interessam.

Dentro de um contexto de ação social mais amplo, em que se concretiza a atuação política das instituições, a importância das ações de cada uma delas tende a ser avaliada em consonância com o foco que demarca a configuração de determinada rede e sob diferentes matizes sociais e políticos assumidos dentro da matriz operacional da respectiva policy websphere, que a circunscreve temática e geograficamente; logo, a análise de redes, em virtude do foco específico de investigação ser direcionado para aqueles aspectos da realidade escolhidos como objeto de pesquisa, tende a considerar apenas parcialmente a dinâmica de atuação de determinada organização num amplo e complexo ambiente sociopolítico.

Essa consideração apenas parcial da realidade ocorre em conseqüência dos critérios utilizados para a definição da pertinência a certa área temática e/ou geográfica; da importância relativa de cada atuação sobre a configuração de diferentes redes em que determinada organização envolve-se; e dos papéis e funções que nelas desempenha. Diante disso, as múltiplas redes em que certa organização pode participar concomitantemente tendem a 
apresentar diferentes morfologias em diversos níveis de diferenciação e configurados em função dos contornos de núcleos temáticos e/ou geográficos.

Diante de tais observações, a perspectiva da policy websphere, como abordagem capaz de delinear macro-ambientes sociopolíticos em que se inserem as redes sociotécnicas de políticas, ganha crescente relevância para a análise de políticas públicas cuja elaboração e execução ocorrem cada vez mais sob a influência e com o apoio das no- vas tecnologias em arranjos interinstitucionais de governança pública.

Concluindo, entendemos que a mais importante contribuição da Policy Websphere Analysis para a compreensão da esfera pública contemporânea, pelo menos até este momento, consiste na possibilidade de delineamento dos novos espaços de apresentação e discussão de informações, idéias, ações e projetos, tendo estes espaços crescente importância para a atuação das redes de políticas em processos de governança pública.

Mario Procopiuck (mario.p@pucpr.br) é Doutorando em Administração pela Pontifícia Universidade Católica do Paraná (PUC-PR).

Klaus Frey (klaus.frey@pq.cnpq.br) é Pós-Doutor em Planejamento Urbano e Regional e em Políticas Públicas pela Technische Universitaet Berlin (TUB), da Alemanha, e Professor Titular da Pontifícia Universidade Católica do Paraná (PUC-PR).

\section{REFERÊNCIAS BIBLIOGRÁFICAS}

BERGER, P. \& LUCKMANN, T. 1985. A construção social da realidade : Tratado de Sociologia do Conhecimento. Petrópolis : Vozes.

BLOM-HANSEN, J. 1997. A "New Institutional" Perspective on Policy Network. Public Administration, v. 75, n. 4, p. 669-693, Winter.

BOURDIEU, P. 2005. O poder simbólico. Rio de Janeiro : Bertrand Brasil.

DUARTE, F. 2002. Crise das matrizes espaciais : arquitetura, cidades, geopolítica, tecnocultura. São Paulo : Perspectiva.

EGLER, T. 2006. Redes técno-sociais e gestão democrática da cidade. Rio de Janeiro : UFRJ. Disponível em : http://acd.ufrj.br/ interacao/ login/login.php. Acesso em : 2.ago.2009.

EVANS, M. 1998. Análisis de redes de políticas públicas : una perspectiva británica. Gestión y Política Pública, Ciudad de México, v. 7, n. 2, p. 229-266.

FOOT, K.; SCHNEIDER, S.; DOUGHERTY, M.; XENOS, M. \& LARSEN, E. 2003. Analyzing Linking Practices : Candidate Sites in the 2002 US Electoral Web Sphere. Journal of Computer-Mediated Communication, Bloomington, v. 8, n. 4, July. Disponível em : http://jcmc.indiana.edu/vol8/issue4/foot.html. Acesso em : 2.ago.2009.
FREY, K. 2000. Políticas públicas : um debate conceitual e reflexões referentes à prática da análise de políticas públicas no Brasil. Planejamento e Políticas Públicas, Brasília, n. 21, jun. Disponível em : http://www.ipea.gov.br/pub/ ppp/ppp21/Parte5.pdf. Acesso em : 2.ago.2009.

2005. ICT-Enforced Community Networks for Sustainable Development and Social Inclusion. In : ALBRECHTS, L. \& MANDELBAUM, S. (org.). The Network Society : a New Context for Planning. London : Routledge.

FRY, J. 2006. Studying the Scholarly Web : How Disciplinary Culture Shapes Online Representations. International Journal of Scientometrics, Informetrics and Bibliometrics, Madrid, v. 10, n. 1.

GUALINI, E. 2005. Reconnecting Space, Place, and Institutions : Inquiring into "Local" Governance Capacity in Urban and Regional Research. In : ALBRECHTS, L. \& MANDELBAUM, S. (org.). The Network Society : a New Context for Planning. London : Routledge.

HANNEMAN, R. \& RIDDLE, M. 2005. Introduction to Social Network Methods. Riverside : University of California. Disponível em : http://faculty.ucr.edu/ hanneman/. Acesso em : 2.ago.2009. 
HEIMERIKS, G. \& BESSELAAR, P. 2006. Analyzing Hyperlinks Networks : the Meaning of Hyperlink Based Indicators of Knowledge Production. International Journal of Scientometrics, Informetrics and Bibliometrics, Madrid, v. 10, n. 1.

IACOBUCCI, D. 1997. Graphs and Matrices. In : WASSERMAN, S. \& FAUST, K. (org.). Social Network Analysis : Methods and Applications. Cambridge, MA: University.

KLIJN, E.-H. 1999. Policy Networks and Network Management : a State of the Art. In : KICKERT, W.; KLIJN, E.-H. \& KOPPENJAN, J. (org.). Managing Complex Networks. Strategies for the Public Sector. London: Sage.

MARCH, J. \& OLSEN, J. 1994. Institutional Perspectives on Governance. In : DERLIEN, H.-U.; GERHARDT, U. \& SCHARPF, F. (hg.). Systemrationalität und Partialinteresse : Festschrift für Renate Mayntz. Baden-Baden : Nomos.

MARQUES, E. 2003. Redes sociais e atores políticos no governo da cidade de São Paulo. São Paulo : Annablume.

PARK, H. 2003. Hyperlink Network Analysis : a New Method for the of Social Structure on the Web. Connections, Alhambra, v. 25, n. 1. p. $49-61$

PARK, H.; BARNETT, G. \& NAM, I. 2002. Interorganizational Hyperlink Networks Among Websites in South Korea. Networks and Communication Studies, Montpellier, v. 16, n. 3-4. p. 155-174.

PARK, H. \& THELWALL, M. 2003. Hyperlink Analyses of the World Wide Web : A Review. Journal of Computer-Mediated Communication, Bloomington, v. 8, n. 4., July. Disponível em : http://jcmc.indiana.edu/vol8/issue4/ park.html. Acesso em : 2.ago.2009.

PRITTWITZ, V. 1994. Politikanalyse. Opladen : Leske-Budrich.

PROCOPIUCK, M. 2007. Governança local e redes sociotécnicas de difusão social de TICs nas cidades de Porto Alegre e Curitiba. Curitiba. Dissertação (Mestrado em Gestão Urbana), Pontifícia Universidade Católica do Paraná.

PROCOPIUCK, M. \& FREY, K. 2007. Redes sociotécnicas de difusão social de TICs em
Porto Alegre e Curitiba. XXXI Encontro da $A N P A D$, Rio de Janeiro.

PROCOPIUCK, M. \& ROSA, A. 2009. Redes sociotécnicas no ciberespaço : possibilidades de avaliação de relações sociopolíticas sobre a Agenda 21 e desenvolvimento sustentável local numa Policy Websphere. XIII Encontro Nacional da ANPUR - Planejamento e Gestão do Território: escalas, conflitos e incertezas, Florianópolis.

ROSA, A. 2007. Rede de governança ambiental na cidade de Curitiba e o papel das tecnologias da informação e comunicação. Curitiba. Dissertação (Mestrado em Gestão Urbana). Pontifícia Universidade Católica do Paraná.

ROSA, A.; FREY, K. \& PROCOPIUCK, M. 2007. Redes virtuais de governança ambiental : análise de uma websphere ambiental a partir da cidade de Curitiba. Revista Tecnologia e Sociedade, Curitiba, v. 5. p. 79-102.

SCHNEIDER, V. \& WERLE, R. 1991. Policy Networks in the German Telecommunications Domain. In : MARIN, B. \& MAYNTZ, R. (org.). Policy Networks : Empirical Evidence and Theoretical Considerations. Frankfurt : Campus.

SCOTT, J. 2000. Social Network Analysis : a Handbook. Thousands Oaks : Sage.

SPINK, P. 2000. The rights approach to local public management : experiences from Brazil. Revista de Administração de Empresas, São Paulo, v. 40, n. 3. p. 45-65, jul.-set.

TOURAINE, A. 1969. Sociologia de la accion. Barcelona : Ariel.

WALKER, J. 2002. Links and Power: The Political Economy of Linking on the Web. In : Conference on Hypertext and Hypermedia. Maryland: ACM.

WASSERMAN, S. \& FAUST, K. 1997. Social Network Analysis : Methods and Applications. Cambridge, MA : University.

WINDHOFF-HÉRITIER, A. 1987. PolicyAnalyse : eine Einführung. New York : Campus.

ZURBRIGGEN, C. 2005. Las redes de politicas públicas. Una revisión teórica. Barcelona : Institut Internacional de Governabilitat de Catalunya. 


\section{OUTRAS FONTES}

A Tunísia e a Conferência Internacional sobre a Sociedade da Informação. 2006. Cultura Livre, Rio de Janeiro, 28.nov. Disponível em : http://www.culturalivre.org.br/index.php? option=com_content\&task=view \&id= 28\&Itemid=58. Acesso em : 2.ago.2009.

ANALYTIC TECHNOLOGIES. 2002a. Ucinet 6 for Social Network Analysis. Disponível em : http://www.analytictech.com/ucinet6/ ucinet.htm. Acesso em : 2.ago.2009.

2002b. NetDraw : Graph Visualization Software. Disponível em : http:// www.analytictech.com/Netdraw/ netdraw.htm. Acesso em : 2.ago.2009. 


\section{PUBLIC POLICY AND GOVERNING NETWORKS AND THEIR ANALYSIS THROUGH "WEBSPHERE ANALYSIS"}

Mario Procopiuck and Klaus Frey

This article presents a discussion on Policy Websphere Analysis as a methodological approach for analysis of organizational arrangements and the relationships they express through cyberspace, in an attempt to make the logics underlying political policies within the context of political networks explicit. Through this approach, we present the results of research aimed at apprehending and interpreting the relational logic of sociopolitical practices meant to facilitate societal dissemination of information and communication technologies, as sustained through the norms and values underlying organizational arrangements, in Porto Alegre and Curitiba. We present a reticular morphology of such arrangements, using of tables that have been put together through websites and hyperlinks and which, in essence, constitute the representative means for potential spaces of political interaction and the socio-political values communicated by organizations that are articulated in governance arrangements represented in virtual space. In our view, the most important contribution made by Policy Websphere analysis, at least until the present, consists of the possibility for delimiting new spaces for the presentation and discussion of ideas, actions and projects. These spaces have acquired an ever-greater importance in political networks' actions in processes of public governance.

KEYWORDS: Policy Websphere Analysis; Hyperlink Analysis; Social Network Analysis; sociotechnical political networks; public governance. 
RÉSEAUX DE POLITIQUES PUBLIQUES ET DE GOUVERNANCE : UNE ANALYSE À PARTIR DE LA WEBSPHERE ANALYSIS

Mario Procopiuck et Klaus Frey

Cet article présente un débat sur la Policy Websphere Analysis comme une approche méthodologique d'analyse de composition organisationnelle et ses relations figurant dans le cyberespace. Nous cherchons à expliciter le raisonnement de politiques publiques dans le contexte des réseaux de politiques. Par cette approche, sont présentés les résultats d'une recherche qui visait à saisir et à interpréter la logique relationnelle, appuyée sur des valeurs et des normes sous-jacentes aux compositions organisationnelles, des pratiques sociopolitiques destinées à rendre possible la diffusion sociale de technologies d'information et communication (TICs) à Porto Alegre et à Curitiba. Nous présentons la morphologie reticulaire de ces compositions, au moyen de graphiques élaborés à partir de sites Internet et hyperlinks qui constituent essentiellement des moyens représentatifs d'espaces possibles d'interaction politique et de valeurs sociopolitiques transmis par des organisations articulées dans des arrrangements de gouvernance représentés dans la sphère virtuelle. Nous comprenons que la contribution la plus importante de Policy Websphere Analysis pour la compréhension de la sphère publique contemporaine, au moins jusqu'à maintenant, consiste en la possibilité de définition des nouveaux espaces de présentation et de discussion d'informations, idées, actions et projets, car ces espaces sont de plus en plus importants pour l'action des réseaux de politiques dans des processus de gouvernance publique.

MOTS-CLÉS : Policy Websphere Analysis ; Hyperlink Analysis ; Social network Analysis ; réseaux sociotechniques de politiques; gouvernance publique. 